\title{
Colour relationalism and the real deliverances of introspection
}

Article

Accepted Version

Roberts, P., Andow, J. and Schmitdke, K. (2014) Colour relationalism and the real deliverances of introspection. Erkenntnis, 79 (5). pp. 1173-1189. ISSN 1572-8420 doi: https://doi.org/10.1007/s10670-014-9600-6 Available at https://centaur.reading.ac.uk/48693/

It is advisable to refer to the publisher's version if you intend to cite from the work. See Guidance on citing.

To link to this article DOI: http://dx.doi.org/10.1007/s10670-014-9600-6

Publisher: Springer

All outputs in CentAUR are protected by Intellectual Property Rights law, including copyright law. Copyright and IPR is retained by the creators or other copyright holders. Terms and conditions for use of this material are defined in the End User Agreement.

\section{www.reading.ac.uk/centaur}

\section{CentAUR}

Central Archive at the University of Reading

Reading's research outputs online 


\title{
Colour relationalism and the real deliverances of introspection
}

\author{
Pendaran Roberts \\ James Andow \\ Kelly Schmidtke
}

August 12, 2014

\begin{abstract}
Colour relationalism holds that the colours are constituted by relations to subjects. Antirelationalists have claimed that this view stands in stark contrast to our phenomenally-informed, pre-theoretic intuitions. Is this claim right? Cohen and Nichols' recent empirical study suggests not, as about half of their participants seemed to be relationalists about colour. Despite Cohen and Nichols' study, we think that the antirelationalist's claim is correct. We explain why there are good reasons to suspect that Cohen and Nichols' experimental design skewed their results in favour of relationalism. We then run an improved study and find that most of our participants seem to be antirelationalists. We find some other interesting things too. Our results suggest that the majority of ordinary people find it no less intuitive that colours are objective than that shapes are objective. We also find some evidence that when those with little philosophical training are asked about the colours of objects, their intuitions about colour and shape cases are similar, but when asked about people's colour ascriptions, their intuitions about colour and shape cases differ.
\end{abstract}

\section{Introduction}

Views about what colours are can be placed into two groups: relationalist and antirelationalist. We define relationalism about any property $\mathrm{P}$ to be the view that $\mathrm{P}$ is constituted by a relation to subjects (possibly inter alia) (Cohen, 2004; 2009, p.10). Relationalists about colour in particular usually also hold that this relation is associated (in some way) with subjects' experiences. Thus, colour relationalism is appealing to subjectivists about colour who believe that the colours are minddependent. Cohen is the most prominent defender of colour relationalism. Cohen's relationalism provides an ecumenical response to variation cases according to which the colours are constituted by relations to subjects such that if an object appears to

This paper is forthcoming in Erkenntnis. The final version is available online through Online First (http://link.springer.com/article/10.1007\%2Fs10670-014-9600-6). This document is our own copy of the final version of this paper, not the official published version. Please do not rely on this version for citations, page references, etc.. a number of minor changes will have been made in the published version. 
be red, then it has a property picked about by "red", which is a relational property (2004; 2009, p.8-12, 24-36). The contemporary dispositionalist view that the colours are dispositions to appear certain ways if viewed (McGinn, 1983; Johnston, 1992) is often also considered to be a kind of relationalism, as many think that the relevant dispositions are constituted by relations to subjects (McGinn, 1996; Noë, 2004; Cohen, 2004; 2009). ${ }^{1}$

We define anti-relationalism as the negation of relationalism. Antirelationalist views about colour are more appealing to objectivists who believe that the colours are mind-independent than relationalist views. Reflectance physicalism is a popular antirelationalist view according to which the colours are dispositions to reflect certain proportions of incident light (a disposition but not one that is constituted by a relation to subjects) (Byrne and Hilbert, 2003; Tye, 2000). Micro-structuralism is an older kind of antirelationalist view according to which the colours are identical with non-dispositional (or categorical) micro-structural properties (Kripke, 1972; Jackson and Pargetter, 1987). Primitivism (in a rather narrow sense of the term) is an up-and-coming antirelationalist view according to which the colours are nonreducible and non-subject involving properties (Yablo, 1995; Westphal, 2005) ${ }^{2}$

Intuitions are taken seriously in the debate between relationalists and antirelationalists. For example, a popular and influential objection to colour relationalism is that the view is opposed to our phenomenally-informed, pre-theoretic intuitions. So, as the objection goes, because relationalism is opposed to these intuitions, we should reject the view. We, along with Cohen and Nichols (2010), shall call this argument, "the introspective rejoinder." Many who have thought about colour can be interpreted as endorsing the introspective rejoinder (at least to some degree) (Armstrong, 1987, p.36-37; Boghossian and Velleman, 1989, p.86; Chalmers 2006, p.56-77ff; Dancy, 1986, p.181; Gibbard, 2006, p.10; Johnston, 1992, p.226-27; Yablo 1995, p.489). ${ }^{3}$ Here are two examples.

But surely [relationalism] misrepresents the phenomenology of colour perception: when we see an object as red we see it as having a simple, monadic, local property of the object's surface. The colour is perceived as intrinsic to the object, in much the way that shape and size are perceived as intrinsic. No relation to perceivers enters into how the colour appears; the colour is perceived as wholly on the object, not as somehow straddling the gap between it and the perceiver. Being seen as red is not like being seen as larger than or to the left of. The 'colour envelope' that delimits an object stops at the object's spatial boundaries. So if colour were inherently relational, $[\ldots]$ then perception of colour would misrepresent its structure - we would be under the illusion that a

1 It is important to recognize that there is dissent. One of the present authors has argued that it is misguided to say that the contemporary dispositionalist view holds that relations to subjects constitute the colours (Roberts, 2013).

2 We do not mean to suggest in this taxonomy that physicalism, functionalism, and primitivism when understood broadly are incompatible with relationalism.

3 Cohen and Nichols' (2010) also interpret each of these philosophers as endorsing the introspective rejoinder. 
relational property is non-relational. Contraposing, given that perception is generally veridical as to colour, colours are not relational $[\ldots]$. (McGinn 1996, p.541-42)

Still, it may be insisted, the relational view of colour [... ] surely goes against ordinary colour experience. When, for example, a rubber ball looks blue to me, I experience blueness all over the facing surface of the ball. Each perceptible part of the ball looks blue to me. And none of these parts, in looking blue, look to me to have a relational property. On the contrary, it may be said, I experience blueness as intrinsic to the surface, just as I experience the shape of the surface as intrinsic to it. This simple fact is one that relational approaches to colour cannot accommodate without supposing that a universal illusion is involved in normal experiences of colour - that colours are really relational properties even though we experience them as non-relational. (Tye 2000, p.152-53)

The introspective rejoinder has been raised with such force and regularity that it is clear many with different theoretical commitments take the rejoinder to be a persuasive argument against colour relationalism (Cohen and Nichols, 2010, p.221). The rejoinder supposes that phenomenally-informed intuitions provide defeasible evidence about the nature of colour (although for readability we will often merely talk of 'pre-theoretic intuitions' or just 'intuitions'). There is good reason to accept this principle about colour, regardless of whether a similar principle holds with respect to things other than colour: The rich phenomenal character of colour experiences is an important guide as to the nature of colour properties. ${ }^{4}$ Indeed, we are inclined to think that any account of colour which ignored the phenomenal character of colour experience would risk failing to give an account of colour, as it would risk changing the subject. So, it is natural to treat intuitions that are informed by how the colours appear in perception as providing defeasible evidence as to the nature of colours. The importance of phenomenally-informed intuitions is also the reason that the rejoinder concerns pre-theoretic intuitions. Any theoretical commitments an individual has are likely to influence their intuitions hence limiting the extent to which their intuitions are based on how the colours look.

As we think that the rich phenomenal character of colour experiences is an important guide as to what the colours are (i.e. their natures), we believe that proponents of relationalist views on colour must take the introspective rejoinder seriously. If the rejoinder is correct about our intuitions, the relationalist risks having to say that our intuitions are somehow misfiring and perhaps that "a universal illusion is involved in normal experiences of colour" (Tye, 2000, p.152-153). With others in the debate, we think this is a problem for the relationalist. While such widespread mistakes and/or illusions are, of course, possible, we think them

$4 \quad$ Our claim here is not a strong one. We think that, with respect to colour, phenomenal character has at least some bearing on representational content in typical, every-day cases. This weak premise is all that is needed to motivate the introspective rejoinder. Accepting it, for example, in no way commits one to any necessary connections between phenomenal character and representational content (i.e. to any form of intentionalism). 
implausible and cannot imagine the relationalist giving a convincing response.

In this article, we demonstrate that the introspective rejoinder is correct about our pre-theoretic intuitions. Cohen and Nichols' (2010) study suggests that about half $(47 \%)$ of their participants are relationalists about colour. Hence, their study provides reason to doubt that the introspective rejoinder is correct about our pretheoretic intuitions. We note a number of reasons to be worried about the design of Cohen and Nichols' study ( $\$ 1)$, and conduct an improved study of our own (§2). Contrary to Cohen and Nichols' results, our findings (§3) suggest that antirelationalism is the pre-theoretically intuitive position. Thus, our study suggests that the introspective rejoinder is accurate about our intuitions. We find some other interesting things. Our results suggest that most ordinary people do not find it less intuitive that colours are objective than that shapes are. We also find some evidence, which amongst other things will be discussed in the final section (§4), that when ordinary people are asked just about the colours of objects, their intuitions about colour and shape cases are similar, but when asked to evaluate people's colour ascriptions, their intuitions about colour and shape cases differ.

\section{Cohen and Nichols' experiment}

Cohen and Nichols ran an experiment to see whether the introspective rejoinder is correct about our pre-theoretic intuitions. They presented participants in an introductory logic class with cases involving putative disagreements about colour and shape properties. ${ }^{5}$ In an effort to prevent participants from using linguistic differences to explain the putative disagreements, participants were provided with a background story involving aliens with perceptual systems that differ from ours. Here is an example.

[Andrew and Abigail are] aliens from different planets. They learn English by reading books, and attain native fluency. Their use of English words is no more different from yours than that of other native speakers of English is from yours. But these aliens have different perceptual systems from ours. Consequently, when the aliens visit Earth on a spaceship and talk with their friend Harry the human, they sometimes disagree about whether a given English word applies to something. Your job is to help us settle these disputes. (2010, p.221)

After receiving this background description, Cohen and Nichols' participants received cases of putative disagreement involving a tomato and the colours red and green, and a compact disc (or CD) and the shapes round and triangular. Their cases were worded as follows:

5 Cohen and Nichols also presented participants with putative disagreement cases involving gustatory properties (sweet, bitter, and sour) as well as cases involving the property deliciousness (2010, p.221). The vast majority of their participants selected the relationalist option for both kinds of properties (2010, p.223-224). We concentrate on shape and colour, because it is these results that are integral to our defence of the introspective rejoinder. 
Andrew [or Abigail] the alien and Harry the human view a ripe tomato [or an ordinary compact disc] in good light, at a distance of 1 metre. Harry says that the ripe tomato is red [or that the CD is round], while Andrew [or Abigail] says that the very same ripe tomato is not red (in fact, he says it is green) [or that the CD is not round (in fact, she says it is triangular)]. (2010, p.222)

After reading the cases, participants were asked to select one of three options. Below are the options that were available.

(1) The tomato is red [or the CD is round], so Harry is right and Andrew [or Abigail] is wrong.

(2) The tomato is not red [or the CD is not round], so Andrew [or Abigail] is right and Harry is wrong.

(3) There is no fact of the matter about unqualified claims like 'the tomato is red' [or 'the CD is round']. Different people have different visual experiences when they look at the same object, and it is not absolutely true or false that the tomato is red [or that the CD is round]. (2010, p.222)

Cohen and Nichols (2010) found that $47 \%$ selected option (3) when presented with the colour case and so seemed to be colour relationalists, and that $30.9 \%$ selected option (3) when presented with the shape case and so appeared to be relationalists about shape. To be clear, option (3) is supposedly the relationalist friendly option, because it suggests that there is a subjectivity in the nature of the colours that the antirelationalist would find troubling but that most relationalists would endorse, especially those of Cohen's ecumenical variety (2004; 2009). Sign tests revealed that participants were more likely to choose the relationalist answer for colours than for shapes. This data suggests, contrary to the introspective rejoinder, that "the introspective capacities available to normal adults do not, by themselves, supply authoritative and unambiguous data about whether the colours are relational" (Cohen and Nichols, 2010, p.226). Thus, Cohen and Nichols' results suggest that there is no sense in which the introspective rejoinder is correct that colour relationalism is opposed to our pre-theoretic intuitions.

Cohen and Nichols' results are contrary to what we would have expected. We first became suspicious of their study after noticing that $30.9 \%$ of their participants selected relationalism about shape. As shapes are very obviously non-relational (in the relevant sense), this suggested that there was something about Cohen and Nichols' experimental design that biased their participants in favour of relationalism. We noticed some other things straight away that struck us as odd. For example, Cohen and Nichols background description includes the stipulation that "[The aliens'] use of English words is no more different from yours than that of other native speakers of English is from yours" (2010, p.221), but then in their cases the aliens use the English words "round" and "red" in ways that are utterly distinct from how normal English-speaking subjects use them (e.g. the aliens say things like "the $\mathrm{CD}$ is not round"). Upon examining their experiment more closely, we discovered four further reasons to be concerned. 
First, their relationalist option, their option (3), is composed of the following three distinct propositions:

(a) There is no fact of the matter about unqualified claims like [e.g. "the tomato is red"].

(b) Different people have different visual experiences when they look at the same object.

(c) It is not absolutely true or false that [e.g. the tomato is red].

This is an unwieldy mixture. One thing that is worrying is that the relationalist option includes (b). Participants may find (b) to be a likely explanation for why Andrew and Harry [or Abigail and Harry] disagree. If different people have different visual experiences when they look at the same object, then this would probably result in, for instance, Andrew and Harry disagreeing about the tomato's colour. Thus, participants may choose the relationalist option in order to choose (b). Unfortunately, (b) is consistent with both relationalism and with anti-relationalism. ${ }^{6}$

Second, given how Cohen and Nichols set up their experiment, the only alternatives to the relationalist option are to commit oneself to saying that Harry is right (option 1) or to commit oneself to saying that Andrew [or Abigail] is right (option 2). So, for the antirelationalist to express their intuitions, they must say that Harry is right or that Andrew [or Abigail] is right. The shape case involves a compact disc. So, Harry is obviously correct and Abigail wrong (assuming she is speaking English), because discs are round by definition. However, it is unobvious whether in the colour case Harry or Andrew (if either) is right. Ripe tomatoes of the common variety are red, but this is not true for all varieties. Thus, Cohen and Nichols' setup may bias antirelationalists towards the relationalist option in the colour case; participants with antirelationalist intuitions may chose the relationalist option in the colour case to avoid saying that Harry is right or that Andrew is right, because they are uncertain which (if either) is right.

Third, Cohen and Nichols' background description, which is supposed to prevent participants from interpreting the disagreement case as being due to linguistic differences, involves aliens with perceptual systems that differ from ours. Participants may find it intuitive that aliens with different perceptual systems do not see colours and shapes (or at least not the same ones that we see) and so plausibly would mean something different from us by "The tomato is red" and "The CD is round." So, Cohen and Nichols' background description may have betrayed its purpose by skewing participants towards treating Harry and Andrew's [or Harry and Abigail's] dispute as being due to linguistic differences. There are reasons to suspect that this third concern would have more of an influence on participants' judgements about colour than their judgements about shape. First, participants may be sensitive to the

6 There is another worry with (b). If one interprets 'different visual experiences' to mean 'numerically different visual experiences,' then (b) is as close to undeniable as anything is in philosophy. So, it is reasonable to hold that upon reflection people would find that (b) is certain under this reading. So, participants may choose the relationalist option to choose (b), because they are certain that (b) is true under the relevant reading. 
idea that seeing shapes is universally important to surviving, but that the importance of being able to see colours (or the colours that we see) is more environmentally dependent. ${ }^{7}$ Second, participants may be sensitive to the idea that there are mathematical definitions for shapes but not for colours that the aliens could rely on to avoid a verbal dispute even if things look somewhat different to them.

Fourth, we are worried that participants may chose the relationalist option in order to express a feeling that no one is at fault. Participants may associate someone being wrong with their being at fault for being wrong, because when one is wrong one is also often at fault for it. Option (1) implies that Andrew [or Abigail] is wrong and option (2) that Harry is. So, because of the association that participants may have, they may feel that by agreeing with (1) they are agreeing that Andrew [or Abigail] is at fault and by agreeing with (2) that Harry is at fault. However, participants may not feel as if either (or both) is at fault for being wrong, because they may think that whether Andrew or Harry [or Abigail or Harry] is wrong (or whether they both are) is due to factors that are outside of their control like a visual system malfunction. Participants may be particularly likely to think this in the colour case because of the well-known phenomenon of colour blindness, an inherited trait for which one is not responsible.

\section{Our method}

We ran an experiment to test pre-theoretic intuitions designed to avoid the problems with Cohen and Nichols' study mentioned above. All 129 of our participants (61 male) completed an online survey. Of the participants, 31 had postgraduate experience in philosophy, including some faculty, and the remaining 98 either had no training in philosophy or at most had completed an undergraduate degree in philosophy. ${ }^{8}$

Participants either received a case involving colour disagreement $(N=65)$ or one involving shape disagreement (but never both) as follows:

Disagreement case Alex and Harry examine an object. Alex and Harry examine the object in typical lighting from the same position. They are both fluent English speakers and have normal eyesight. Harry says that the object is red [or round], while Alex says that the very same object is green [or cube shaped].

After reading either a colour or shape case, participants were asked to evaluate 7 statements on a likert scale with 10 items from disagree to agree:

Epistemic We could find out who is right about the colour [or shape] of the object.

7 There is empirical evidence that the importance of being able to see colours is environmentally dependent. For example see, Changizi et al, 2006.

8 These participants were recruited in two sections. The first 67 participants were recruited spring 2013 using social media and through the University of Nottingham. The remaining 62 participants were recruited autumn 2013 through the University of Warwick's Behavioural Science Group's participant recruitment system. 
Fault One of them, and possibly both, is at fault for getting the colour [or shape] wrong.

Appearance The object may appear in different ways to Alex and Harry, and so, for all we know, both of them could be correctly reporting how the object appears to them.

Meaning Alex and Harry may only disagree about what the words "red" and "green" [or "round" and "cube shaped"] mean, and so given how they may be individually using the words, they could for all we know both be right about the colour [or shape] of the object.

Verbal People often disagree about what word best describes how an object appears. For example, people often disagree about whether something should be called "red" or "orange" [or "round" or "cube"].

Perceptual People disagree a lot about what colours [or shapes] things perceptually appear to have.

Target In reality, there is an absolute fact of the matter about the colour [or shape] of the object regardless of how it appears to Alex and Harry and regardless of what they think, say, or do.

Note that Target is about the colour [or shape] of the object. The reason why Target is phrased this way is that relationalism and anti-relationalism are metaphysical views and not views on how people use colour [or shape] language. An additional reason for this phrasing concerns Cohen's $(2007 ; 2009)$ distinction between fine/coarse-grained colours. When it comes to fine-grained colours, everyone is more or less guaranteed to be right according to Cohen. However, Cohen seems to hold that typically people ascribe (in language) coarse-grained colours to objects. Coarse-grained colour properties are such that error can much more easily occur, because these colours are constituted by relations that hold between objects and normal observers and conditions. Given this subtlety in Cohen's account, it would be difficult to interpret a question about colour ascriptions rather than the colours themselves, hence we decided to focus only on the latter.

The order of the first six statements above was randomized, but Target always came last. We did this because we were worried that participants would disagree with Target in order to express something unrelated to their relationalist intuitions and hoped that the first six statements would help to disambiguate Target so that this would not happen. For example, we had a concern, similar to our final worry with Cohen and Nichols' study, that participants would disagree with Target in order to express that no one is at fault for being wrong about the object's colour or shape. Participants may think that by agreeing with Target they are agreeing with the proposition that Alex is at fault or Harry is (or that both are at fault) for being wrong. ${ }^{9}$

$9 \quad$ There are various reasons why disambiguating statements like Target is important in experimental philosophy. One should not assume that participants will understand terms like "truth", "fact of the matter", "correct" and "accurate" the way we do. This is a lesson we can learn from the work of the "Oslo School", e.g., Arne Naess and Herman Tennesen-work which is sometimes touted 


\section{Our results}

The majority of our participants responded 6 to 10 on Target indicating some degree of agreement with anti-relationalism in both the colour (72.30\%) and the shape (85.90\%) conditions. Interestingly, the results suggest different trends depending on the level of experience that participants have in philosophy. Among those with postgraduate experience in philosophy (including university faculty), call this group 'Philpost', fewer participants agreed with anti-relationalism about colour (64.70\%) than shape (92.90\%). In comparison, among those who either had no experience in philosophy or whose highest experience in philosophy was at an undergraduate level, call this group 'Not-Philpost', a more similar number of participants agreed with both anti-relationalism about colour (75.00\%) and shape (84.00\%), see fig.1, p.10.

Are there any significant differences for property type (colour, shape)? The Mann-Whitney U test, a nonparametric alternative to a t-test, indicated no significant difference between the way Target was rated in colour and shape conditions on a scale of $1-10$ when all participants were analyzed $(z=1.76, p=0.08)$, although the result did approach significance. This result was driven by those in Philpost. We find no evidence of a difference whatsoever in Not-Philpost between the way colour and shape were rated $(\mathrm{z}=0.84, \mathrm{p}=0.41)$. Contrary to this, we find that the likert ratings are different for colour and shape in Philpost $(\mathrm{z}=2.07, \mathrm{p}<0.05)$. There is no evidence that those in Not-Philpost recognize a difference between colour and shape. ${ }^{10}$

The Mann-Whitney U test was performed on the six disambiguating statements to test for a difference between the way colour and shape were rated when all participants were analyzed together and then for the subgroups. We did this because we were interested in exploring how our participants understand colour and shape cases, and thought that we might learn something interesting by looking at how our participants rated the disambiguating statements in depth. For all participants, differences were found for Appearance $(\mathrm{z}=2.18, \mathrm{p}<0.05)$, Verbal $(\mathrm{z}=5.80, \mathrm{p}$

as early experimental philosophy. Another illustrative example is that of Fain and Kaelin (1960) who, in a similar early empirical study, found an astonishing level of agreement among philosophy undergraduates that all or most truths are relative (at the beginning of term $80 \%$ and $83 \%$ in consecutive years, and at the end of term $65 \%$ and $56 \%$ ). On further investigation they found that "when a student says that the same proposition can be true for one person and false for another, he usually means something quite innocent: that the same proposition can be believed and disbelieved by different people at the same time" (p.142).

10 A critic might note that our between-subjects design could hide within-subject differences, like the results Cohen and Nichols found. To mitigate these concerns, 52 willing participants from the University of Warwick were sent a second survey about whichever property they did not respond to originally in a follow up email a week later. In total, 37 participants responded to the second survey (18 colour).

Descriptively, the participants' responses to Target for both colour and shape are very similar. For colour the median response was eight; while for shape the median response was nine. Notably, the modal responses for both colour and shape were 10. Statistically, these results were compared with a sign test, a non-parametric alternative to the repeated samples t-test. The test found no difference between participants' colour and shape responses $(\mathrm{z}=1.24, \mathrm{p}=0.21)$. Thus, even employing a within-samples design, like Cohen and Nichols, we find no difference between participants' colour and shape Target responses. 


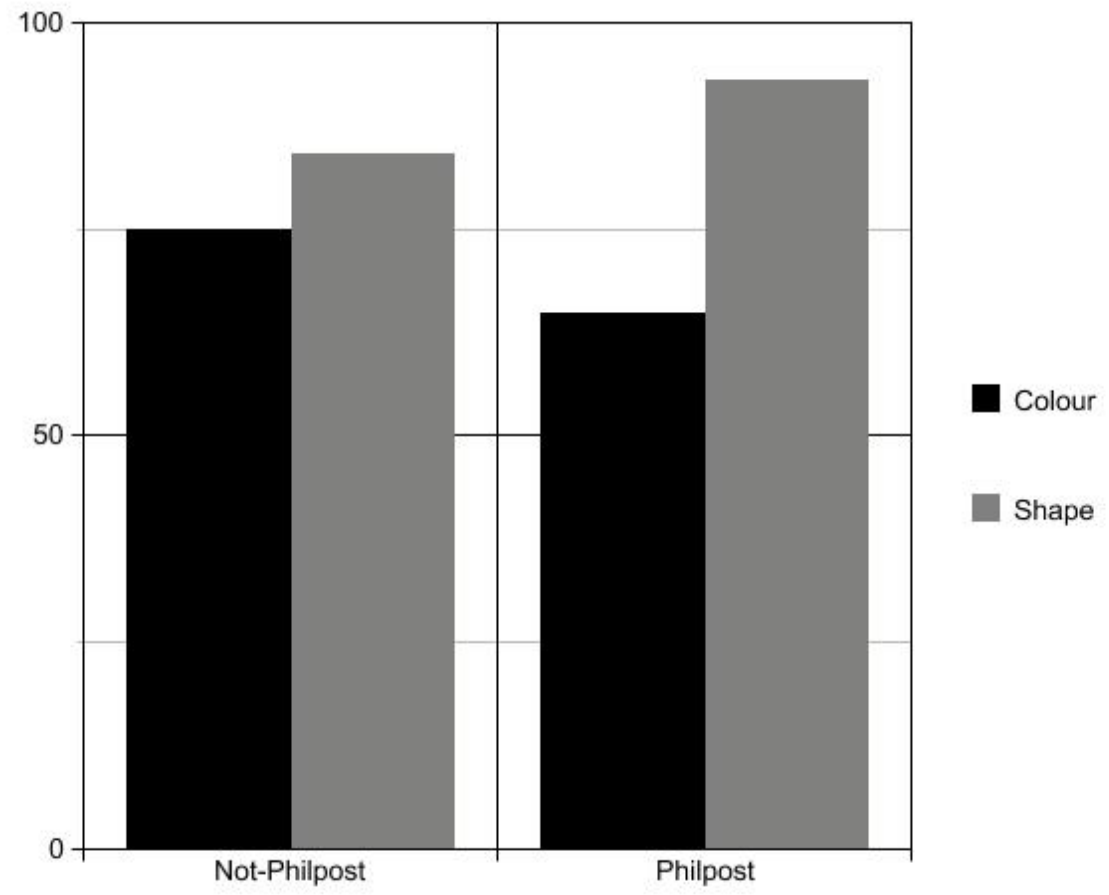

Figure 1: The percentage of participants divided into Not-Philpost and Philpost, and colour and shape cases who indicated some agreement (likert scale 6-10) with anti-relationalism.

$<0.01$ ), and Perceptual $(\mathrm{z}=2.83, \mathrm{p}<0.01)$. For Not-Philpost the differences remained for Verbal $(\mathrm{z}=5.62, \mathrm{p}<0.01)$ and Perceptual $(\mathrm{z}=2.66, \mathrm{p}<0.01)$. In contrast, none of the differences were significant for Philpost, with only Perceptual approaching significance $(\mathrm{z}=1.90, \mathrm{p}=0.06)$.

We further examined the relationships between all seven statements using Spearman's rho correlation matrices. For simplicity, we will only talk about the results found when analyzing all of the participants together. Table 1 (p.11) is included for anyone interested in whether the correlations hold for the subgroups and notes some differences between them. Our findings support some of our concerns with Cohen and Nichols' study and shed light on the Mann-Whitney differences found for Target, Appearance, Verbal, and Perceptual.

Interesting patterns were observed for Target between the colour and shape correlation matrixes. When looking at participants' responses to the colour case, we found that Target correlates with both Epistemic and Fault (respectively, $\mathrm{r}=$ $0.52, p<0.01 ; \mathrm{r}=0.40, \mathrm{p}<0.01$ ). In contrast, for participants' responses to the shape case, Target was found to only correlate with Epistemic $(r=0.35, \mathrm{p}<0.01)$. The discovery that Fault is uniquely associated with participants' responses to Target in the colour case supports our fourth concern with Cohen and Nichols' study. This 
Table 1: Spearman's Rank Order correlations for all participants and across subgroups.

\begin{tabular}{|l|l|l|l|l|l|l|}
\hline & \multicolumn{2}{|c|}{ All participants } & \multicolumn{2}{c|}{ Not-Philpost } & \multicolumn{2}{c|}{ Philpost } \\
\hline Spearman's Rank Order & Colour & Shape & Colour & Shape & Colour & Shape \\
Correlations & $\mathrm{N}=65$ & $\mathrm{~N}=64$ & $\mathrm{~N}=48$ & $\mathrm{~N}=50$ & $\mathrm{~N}=17$ & $\mathrm{~N}=14$ \\
\hline Target - Epistemic & $* *$ & $* *$ & $* *$ & $* *$ & $*$ & \\
Target - Fault & $* *$ & & $* *$ & & $* *$ & \\
Epistemic - Fault & $* *$ & & $* *$ & & $* *$ & \\
Appearance - Meaning & $*$ & $* *$ & $* *$ & $* *$ & & $* *$ \\
Appearance - Verbal & $*$ & & $* *$ & & & \\
Appearance - Perceptual & $*$ & & $* *$ & $*$ & & \\
Appearance - Fault & & $*$ & & $*$ & & \\
Verbal - Meaning & $*$ & & & $* *$ & & \\
Verbal - Perceptual & $* *$ & $* *$ & $* *$ & $* *$ & $* *$ & $*$ \\
Perceptual - Meaning & $*$ & & & & & \\
\hline$*$ p $<0.05 * * \mathrm{p}<0.01$ & & & & & &
\end{tabular}

$* \mathrm{p}<0.05$. ** $\mathrm{p}<0.01$

worry was that Cohen and Nichols' participants may choose the relationalist option in the colour case in order to avoid attributing fault to the relevant parties. The fact that Fault is uniquely associated with participants' colour responses supports our fourth concern, because it corroborates what one would expect to find if participants in Cohen and Nichols' study were choosing the relationalist option in the colour case in order to avoid attributing fault: If participants were choosing the relationalist option to avoid attributing fault, one would expect those who chose this option to disagree with a statement that attributes fault.

Examining Appearance we find that there is a significant relationship between this statement and Meaning for both the colour and shape cases (respectively, $\mathrm{r}$ $=0.31, \mathrm{p}<0.05 ; \mathrm{r}=0.50, \mathrm{p}<0.01$ ). The correlation between Appearance and Meaning supports our third worry with Cohen and Nichols' study that their background description using aliens with unique perceptual systems might have led their participants to believe that the dispute between the aliens and the humans is only due to linguistic differences. This correlation supports our third worry because it is exactly what one would expect to find if the worry were correct: If differences in how things appear, which would plausibly result from the aliens having different perceptual systems, lead participants to think there is merely a linguistic dispute going on, one would expect the discovered correlation to obtain. Our third worry could explain why Cohen and Nichols' study seemed to find such a large percentage of relationalists about both colour and shape.

We found three more correlations having to do with Appearance. For the colour case we find a significant relationship between Appearance and Verbal $(\mathrm{r}=0.27, \mathrm{p}$ $<0.05$ ). This was to be expected, for if something looks different to two people, they are likely to use different words to describe that thing. For the colour case we also find a significant relationship between Appearance and Perceptual $(\mathrm{r}=0.29$, $\mathrm{p}<0.05$ ). This was also to be expected, because intuitively differences in how things appear lead to perceptual differences. Interestingly, we find neither of these 
correlations for the shape case. This absence probably has something to do with the fact that shapes have mathematical definitions that go beyond how they look. For the shape case we find a relationship between Appearance and Fault $(\mathrm{r}=-0.27$, $\mathrm{p}<0.05$ ). Interestingly, we do not find this correlation for the colour case. The explanation for this is difficult to see.

From examining Verbal, we find an interesting difference between participants' colour and shape responses. When looking at participants' responses in the case of colour a correlation emerges between Verbal and Meaning $(r=0.29, p<0.05)$. This correlation was to be expected, because it is intuitive that two people whose colour terms have different meanings would end up using different colour terms to describe the same object (i.e., to verbal differences). However, interestingly, this relationship is not significant for the shape analyses. This suggests that the connection between Verbal and Meaning is stronger for colour than shape. Perhaps this is because people are not as willing to allow shape terms to have alternative meanings as they are willing to allow colour terms to. This in turn may have something to do with the fact that shapes have mathematical definitions. ${ }^{11}$

We shall now look at Perceptual. We observed a correlation between this statement and Meaning for participants' responses in the colour case $(r=0.28, \mathrm{p}<0.05)$. This finding, like the finding regarding the relationship between Appearance and Meaning, supports our third worry with Cohen and Nichols' study. The third worry, again, is that Cohen and Nichols' background description involving aliens with different perceptual systems might have led their participants to think that the dispute between the aliens and the humans is only due to linguistic differences. The correlation supports this worry because it corroborates what one would expect to find if the worry were correct: If perceptual differences, which would likely result from the aliens having different perceptual systems from humans, lead participants to think there is merely a linguistic dispute going on, one would expect the mentioned correlation to obtain. Moreover, it seems we may have been right to suspect that the background description involving aliens would have more of an impact on participants' colour than shape judgements; we find no significant relationship between Perceptual and Meaning for shape $(\mathrm{r}=0.08, \mathrm{p}=0.51)$.

\section{Discussion}

Cohen and Nichols' study called the introspective rejoinder into question, because their results suggested that the introspective capacities available to ordinary people do not provide unambiguous data about whether the colours are relational (2010, p.226). This is a problem for the introspective rejoinder, because if our introspective capacities do not provide unambiguous data, then there is no sense in which it is correct to say that colour relationalism is opposed to our pre-theoretic intuitions. However, compared with $53.00 \%$ of Cohen and Nichols' participants, $72.30 \%$ of our participants, and $75.00 \%$ for Not-Philpost, indicated agreement with anti-relationalism about colour. Thus, our results suggest that things are not nearly

11 A significant correlation also emerged between Verbal and Perceptual for both colour and shape cases. This correlation was to be expected and suggests that participants were paying attention. 
as ambiguous as Cohen and Nichols' study would have us believe. In fact, our data suggests that anti-relationalism is clearly the pre-theoretically intuitive position.

As we said in the results section, only in Philpost were participants significantly less antirelationalist about colour than about shape. It is interesting to speculate about why this might be. Here is a thought. Perhaps philosophers are subject to something like a mere-exposure effect (for classic discussion of such effects see Zajonc, 1968). Philosophers may have more relationalist intuitions because they encounter the idea that colours are somehow less objective than shapes more frequently than the folk due to historical or sociological reasons. Starting with Galileo, Descartes, and Locke (amongst others) there has been an idea in philosophy that colours are (in some sense) less objective (or real) than shapes (Hacker, 1987). Locke is perhaps the most famous for this view. In the Essay he said, "Let not the Eyes see Light or Colours [...] and all Colours [...], as they are such particular ideas, vanish and Cease, and are reduced to their Causes, i.e. Bulk, Figure, and Motion of Parts" (1996, II-viii-17). At any rate, as we found that only in Philpost were participants less antirelationalist about colour than shape, it seems that it is not widely held amongst ordinary people that colours are less objective than shapes. This is of course compatible with colours being less objective than shapes, but it is a reason for caution: The intuitive position seems to be that colours are no less objective than shapes.

Our results seem to suggest that some $(27.70 \%$ all groups and $25.00 \%$ NotPhilpost) of our participants have relationalist intuitions about colour. However, there is reason to doubt whether all those who selected the relationalist response (15 on Target) were really expressing intuitions that accord with colour relationalism as its main proponents understand it. Cohen has devoted the most ink to defending colour relationalism, and relationalism of Cohen's variety is an ecumenical view according to which if an object appears to be red, for instance, it has a property picked out by the English word "red", which for Cohen is a relational property (Cohen 2004; 2009, p.24). However, we found a significant positive correlation between participants' answers to Epistemic and Target. In fact, in the colour case, 17 out of 19 who disagreed with Target disagreed with Epistemic. So, there is some reason to doubt whether most of those who disagreed with Target can be said to be relationalists in Cohen's sense.

Cohen may respond to this by invoking his fine/coarse-grained distinction. As noted previously, coarse-grained colours, unlike fine-grained ones, are constituted by relations to normal observers and conditions so that with respect to these colours error can more easily occur. So, Cohen may try to appeal to his coarse-grained colours to explain why 17 out of 19 who disagreed with Target disagreed with Epistemic. Specifically, he may suggest that participants treat Alex and Harry as referring to coarse-grained colours. He may say that if Alex and Harry do so refer, at most one would be right, but it may be difficult (perhaps impossible) to determine which if either of them is right. In our opinion, the problem with this move is that, according to Cohen, coarse-grained colours are constituted by relations to normal observers and conditions, and the disagreeing parties in our case (Alex and Harry) are stipulated to be normal observers in typical (i.e. normal) conditions. Hence, it seems that Alex and Harry should both be right according to Cohen whether they 
are talking about fine-grained or coarse-grained colours. Thus, this response on behalf of Cohen does not look promising.

Our curiosity about the correlation between Target and Epistemic prompted us to ask some of our participants to respond to an additional case after responding to the other items $\left(\mathrm{N}=62\right.$, all Not-Philpost). ${ }^{12}$ The cases are as follows:

Alex is correct when he says that the object is green [or cube-shaped], and in addition Harry is correct when he says the object is red [or round]. In other words, both Alex and Harry's claims are correct.

Participants in the colour condition received the colour version of this case and participants in the shape condition received the shape version. After reading the case, participants stated whether they disagreed or agreed with the following:

Above-True. The above statement is true.

Above-False. The above statement is false.

For both colour and shape cases, participants largely disagreed with Above-True (colour $=58.10 \%$, and shape $=80.60 \%$ ) and agreed with Above-False (colour $=$ $64.50 \%$, and shape $=74.20 \%$ ). Put another way, more people than not seem to find it intuitive that two colour or shape ascriptions of properties that most philosophers deem incompatible cannot both be correct at the same time. The likelihood that shape and colour responses are different was examined with the chi-square test. For Above-True the chi-square test is almost significant $\left(\chi^{2}(1, N=\right.$ $62)=3.72, p=0.05$ ). This result suggests that people are more likely to agree that two observers can correctly ascribe colour properties that most philosophers deem incompatible than they are likely to agree that two observers can correctly ascribe shape properties that most philosophers deem incompatible. However, it should be noted that for Above-False the differences did not approach significance.

These results are very intriguing when compared to our original results using Target. This statement is only about the colour of the object and is not phrased so as to ask whether Alex and Harry's colour ascriptions are correct. This is as it should be, because relationalism and anti-relationalism about colour are metaphysical views on the nature of colour and not views on how people use colour terms. However, the new case was phrased so as to ask about Alex and Harry's colour ascriptions, because we wanted to see whether most of those who disagreed with Target find it intuitive that at most one party is right. The difference in phrasing between Target and the new case allowed us to inadvertently discover something intriguing: When those in Not-Philpost are asked only about the colours of objects, their intuitions about colour and shape are similar, but when asked about observers' colour ascriptions, their colour and shape intuitions seem to differ.

We explored this difference by looking at Above-True's correlations with the seven original statements. For shape significant correlations appeared only between Above-True and Target and Above-True and Epistemic (respectively, $\mathrm{r}=-0.38$,

12 This additional case was presented only to participants recruited in the second section through the University of Warwick (see footnote 8). The correlation between Target and Epistemic was first brought to our attention when considering the responses of participants in the first section. 
$\mathrm{p}<0.05 ; \mathrm{r}=-0.41, \mathrm{p}<0.05)$. This suggests that whether people find it intuitive that two observers can correctly ascribe to objects shape properties that most philosophers deem incompatible may be due to epistemic factors. For colour no significant correlations emerged. We find this puzzling. Regardless, it does show that we cannot say that most of those who disagreed with Target in the colour case find it intuitive that at most one party is right. Moreover, it certainly seems that we inadvertently discovered another reason to be worried about Cohen and Nichols' experiment: Their options (1)-(3) emphasized colour ascriptions, but we have shown that it cannot be assumed that how people answer questions about colour ascriptions will map onto their answers about the colours of objects. Relationalism and anti-relationalism are not views about language but about properties.

At this juncture it is important to consider some objections. One objection runs as follows: One could adopt relationalism about colour as a solution to interpersonal, intrapersonal, or interspecies variation, or some combination of these types of variation, or all of these types of variation. The experiment we performed only uses a case that involves interpersonal variation between Alex and Harry. Thus, as the objection goes, there is a worry that our experiment is only relevant to relationalism as a view designed to account for interpersonal variation. In reply, the crucial statement in our experiment, called Target, that we asked participants whether they agree with is as follows: In reality, there is an absolute fact of the matter about the colour [or shape] of the object regardless of how it appears to Alex and Harry and regardless of what they think, say, or do. If one agrees with this statement, then it is unlikely that one finds it intuitive that the colours are constituted by relations to subjects, because by agreeing with the statement one is endorsing the claim that the colour of the object is independent of how it appears to Alex and Harry and independent of what they think, say, or do. Thus, we think that that our experiment, regardless of how our case is stated, is relevant to all forms of relationalism as we define the view. We are happy to admit that a participant's agreeing with Target does not rule out his having intuitions that accord with relationalism in some broader sense.

Here is another potential objection. Our opponent may grant that phenomenally informed intuitions are a good guide when theorizing about colour, but challenge the assumption that phenomenology plays any significant role in informing our participants' responses. We can only think of two factors to which an opponent may appeal. They are as follows:

(1) In a pilot study, we found that some participants appealed to quasi-scientific theories of colour, e.g., red is a particular wavelength of light. Perhaps participants' responses were influenced by such a theory and not by their phenomenology.

(2) In the same pilot study, some participants appealed to colour-blindness cases. Perhaps those for whom such cases were salient distanced themselves from any influence of their own experience due to some sort of epistemic humility.

That is the best we can do, and we are prepared to be fairly flat-footed in response. The strong correlation between Fault and Target weighs heavily against 
(2) being a major influence. If drawn to anti-relationalism due to some sort of epistemic humility, one would not expect participants to agree that 'One of them, and possibly both, is at fault for getting the colour wrong'. The fact that only a small number of participants (5/67) in our pilot explicitly appealed to quasi-scientific views weighs against (1). ${ }^{13}$ It is possible that the number influenced (perhaps tacitly) by such views was really much higher. However, absent any concrete reason to think that this is the case, we are not worried. It seems plausible that when it comes to something as visual as colour that for most people phenomenology would be the principal influence; when one thinks of a colour it is the phenomenal character of that colour that is foremost before one's mind.

Here is a third worry about our study. One may object that we should not ignore that a number of our participants $(27.70 \%$ all groups and $25.00 \%$ Not-Philpost) indicated agreement with relationalism. The problem with this one may say is that we cannot be certain that the majority's responses, rather than the minority's, accurately indicate phenomenally-informed intuitions or even whether everyone's phenomenology is relevantly similar (Cohen and Nichols, 2010, p.255-226). There are two objections here, one on either side of the disjunction. In reply to the former, we find it way more plausible that about $28 \%$ of our participants are failing to indicate phenomenally-informed intuitions than that about $72 \%$ are. As we said, it seems plausible when it comes to something as visual as colour that for most people phenomenology would be the principal influence. So, absent an argument against this, we are not worried. Further, the fact that participants in Not-Philpost are just as (statistically) likely to be relationalist about colour as about shape supports our claim that the minority are failing to indicate phenomenally-informed intuitions. Shapes very obviously appear non-relational.

In reply to the latter objection, we find it highly implausible that for some people the colours phenomenally appear relational and for others anti-relational. We suspect that everyone enjoys the same colour phenomenology; that the $72 \%$ were accurately indicating phenomenally-informed intuitions, and that the $28 \%$ just did not understand the questions as intended (see footnote 9) and/or were theoretically biased in some way. However, it is possible that we are wrong. Maybe people really do have divergent colour phenomenology. This is an empirical matter and one we would be incredibly interested to investigate, although we are not sure how to. If we are wrong, then that would be extremely interesting. It would raise all sorts of issues concerning the method of relying on phenomenally-informed intuitions. For example, if the colours really do phenomenally appear relational to some and anti-relational to others, are we to infer that there are really two different types of colour property, relational ones and non-relational ones? Notice that if that is what should be inferred, the whole debate between relationalists and antirelationalists would be undermined; neither view admits the metaphysical possibility that both relational and non-relational colours exist. Regardless, the full repercussions of divergent phenomenology are not something we can explore here.

We are confident, contrary to Cohen and Nichols, that anti-relationalism about

13 The fraction $5 / 67$ represents the proportion of participants who appealed to quasi-scientific views across three variants of a pilot study run in Autumn 2012. 
colour is in accordance with our phenomenally-informed, pre-theoretic intuitions and so is likely the correct view on colour. One may worry that such an inference supposes that being in accordance with our phenomenally-informed, pre-theoretic intuitions is evidence that anti-relationalism is true. However, as we noted, such a principle seems plausible in the case of colour, as it flows from the idea that the phenomenal character of colour experiences is an important guide as to the nature of the colours. It is open to our opponents to argue against the principle. This has not been done, and we cannot imagine it being done convincingly.

$$
\begin{array}{r}
\text { Pendaran Roberts, } \\
\text { pendaran@me.com } \\
\text { James Andow, } \\
\text { james.andow@nottingham.ac.uk } \\
\text { Kelly Schmidtke, } \\
\text { kelly.schmidtke@wbs.ac.uk }
\end{array}
$$

\section{Acknowledgements}

We are especially grateful to Philip Percival, Jonathan Tallant, and Joshua Knobe for helpful comments. We would also like to thank an anonymous referee.

\section{References}

Armstrong, D. 1987. Smart and the secondary qualities. In Metaphysics and Morality: Essays in Honour of J. J. C. Smart, eds. P. Pettit, R. Sylvan and J. Norman. Oxford: Basil Blackwell. Reprinted in Byrne and Hilbert 1997, 33-46.

Boghossian, P. and J. Velleman. 1989. Colour as a secondary quality. Mind 98: 81-103. Reprinted in Byrne and Hilbert 1997, 81-103.

Byrne, A. and D. Hilbert. 2003. Colour realism and colour science. Behavioral and Brain Sciences 26: 3-64.

Chalmers, D. 2006. Perception and the fall from Eden. In Perceptual Experience, eds. T. Gendler and J. Hawthorne. New York: Oxford University Press. pp. 49-125.

Changizi, M. A., Zhang, Q., and Shimojo, S. 2006. Bare skin, blood and the evolution of primate colour vision. Biology Letters 2: 217-221.

Cohen, J. 2004. Colour properties and colour ascriptions: a relationalist manifesto. The Philosophical Review 113: 451-506. 
Cohen, J. 2007. A relationist guide to error about colour perception. Nous 41: 335-353.

Cohen, J. 2009. The Red and the Real: An Essay on Colour Ontology. Oxford: Oxford University Press.

Cohen, J. and Nichols, S. 2010. Colours, colour relationalism, and the deliverances of introspection. Analysis 70: 218-228.

Dancy, J. and Hookway, C. 1986. Two conceptions of moral realism. Proceedings of the Aristotelian Society. Supplementary Volume 60: 167-87.

Fain, H., and Kaelin, E.F. 1960. Student Philosophical Opinions: A Survey. Inquiry 3: $137-152$.

Gibbard, A. 2006. Moral feelings and moral concepts. In Oxford Studies in Metaethics 1, ed. R. Schafer-Landau. Oxford: Clarendon Press. pp. 195-215.

Hacker, P. M. S. 1987. Appearance and Reality. Oxford: Basil Blackwell.

Jackson F., and Pargetter, R. 1987. An objectivist guide to objectivism about colour. Revue Internationale do Philosophie 41: 127-147.

Johnston, M. 1992. How to speak of the colours. Philosophical Studies 68: 221-63. Reprinted in Byrne and Hilbert 1997, 137-76.

Kripke, S. 1972. Naming and necessity. Cambridge: Harvard University Press.

Locke, J. 1996. An essay concerning human understanding. Indianapolis, ID: Hackett (Original Work Published in 1689).

McGinn, C. 1983. The Subjective View: Secondary Qualities and Indexical Thoughts. Oxford: Oxford University Press.

McGinn, C. 1996. Another look at colour. The Journal of Philosophy 93: 537-53.

Noë, A. 2004, Action in perception. Cambridge, MA: MIT Press.

Roberts, P. (2013). Parsing the rainbow. Synthese.

doi:10.1007/s11229-013-0368-z

Tye, M. 2000. Consciousness, Colour, and Content. Cambridge, Massachusetts: MIT Press.

Westphal, J. 2005. Conflicting appearances, necessity, and the irreducibility of propositions about the colours. Proceedings of the Aristotelian Society 105: 219-235.

Yablo, S. 1995. Singling out properties. Philosophical Perspectives 9: 477-502.

Zajonc, R. B. (1968). Attitudinal Effects of Mere Exposure. Journal of Personality and Social Psychology, Monograph Supplement 9, 1 - 27. 